\title{
EKSPLORASI DAN PENGGABUNGAN MESIN PADA SENI PATUNG
}

\author{
Lutse Lambert Daniel Morin ${ }^{1}$ (Fakultas Seni Rupa, Institut Seni Indonesia Yogyakarta)
}

\begin{abstract}
One type of artwork in three dimensions is sculpture. As part of fine art, sculpture is an artistic and aesthetic statement through three-dimensional forms. Each form of car or motorcycle engine is unique. The number of machines that can no longer be used and are only piled up in the trash or even in a flea collector and destroyed again to be used as a material for machine makers that gave rise to the idea of utilizing the metal waste into three-dimensional art forms. The technique used in the embodiment of art is construction using welding and screw raft techniques. The machines will be arranged and integrated in such a way as to form a three-dimensional work according to the basic idea of making the work.
\end{abstract}

Keywords: Exploration, Machine, Sculpture

\section{ABSTRAK}

Salah satu jenis karya seni yang berbentuk tiga dimensi adalah seni patung. Sebagai bagian dari seni rupa, seni patung merupakan pernyataan artistik dan estetik melalui bentuk-bentuk tiga dimensional. Setiap bentuk mesin mobil maupun motor memiliki keunikan yang berbeda-beda. Banyaknya mesin-mesin yang sudah tidak bisa digunakan lagi dan hanya ditumpuk di tempat sampah atau bahkan di tukang loak dan dihancurkan lagi untuk dijadikan bahan pembuat mesin yang baru memunculkan ide untuk memanfaatkan limbah logam tersebut ke dalam bentuk seni tiga dimensi. Teknik yang digunakan dalam perwujudan karya seni adalah konstruksi menggunakan teknik rakit las dan sekrup. Mesin-mesin akan disusun dan dipadukan sedemikian rupa sehingga membentuk karya tiga dimensi seuai dengan ide dasar pembuatan karya.

Kata Kunci: Eksplorasi, Mesin, Patung

\section{PENDAHULUAN}

Seni menjadi sesuatu yang dibutuhkan dalam kehidupan. Seni mampu memberikan nilai keindahan yang mampu menarik perhatian dan perasaan setiap orang yang melihatnya. Hal ini seperti diungkapkan oleh Soedarso SP bahwa seni adalah segala macam keindahan yang diciptakan manusia.
Seni merupakan produk keindahan yaitu suatu usaha manusia untuk menciptakan yang indah-indah yang dapat mendatangkan kenikmatan (Soedarso,1988:1).

Berdasarkan uraian tersebut di atas, dapat dikatakan bahwa seni pada hakekatnya merupakan hasil ekspresi manusia (seniman) yang bertujuan untuk mendatangkan 
kenikmatan di dalam kehidupannya. Sebuah karya seni tercipta dari tangan seniman sebagai hasil ekspresi diri.

Salah satu jenis karya seni yang berbentuk tiga dimensi adalah seni patung. Sebagai bagian dari seni rupa, seni patung merupakan pernyataan artistik dan estetik melalui bentuk-bentuk tiga dimensional. Seni patung ini menggunakan berbagai media digunakan dalam penciptaan karya tiga dimensional ini antara lain kayu, batu, maupun logam. Dalam penciptaan ini, penulis akan memadukan berbagai bentuk mesin-mesin menggunakan teknik las dan rakit hingga membentuk sebuah karya tiga dimensi.

Setiap bentuk mesin yang digunkan memiliki keunikan yang berbeda-beda. Misalnya seperti gerigi mesin. Setiap mesin memiliki beberapa gerigi dengan bentuk yang berbeda-beda. Contoh lain misalnya pir. Seperti gerigi, pir juga memiliki variasi bentuk dan ukuran yang berbeda-beda tergantung dari besar kecilnya mesin dan fungsi dari mesin tersebut.

Hal lain yang menjadikan keteretarikan menggunakan mesin sebagai inspirasi pembuatan karya taiga dimensi adalah banyaknya mesin-mesin yang sudah tidak bisa digunakan lagi dan hanya ditumpuk di tempat sampah atau bahkan di tukang loak dan dihancurkan lagi untuk dijadikan bahan pembuat mesin yang baru.

Berdasarkan latar belakang tersebut diatas, akan dopadukan bentuk-bentuk mesin sehingga akan menghasilkan bentuk karya tiga dimensi yang memiliki nilai artistik. Teknik yang akan digunakan dalam pembentukan karya tiga dimensi ini adalah teknik konstruksi yang akan memadukan pengguanaan mesin yaitu alat las dan manual yaitu merakit menggunakan beberapa skrup.

\section{Tinjauan Pustaka}

Ada beberapa karya yang menjadi inspirasi penulis dalam menciptakan karya seni tiga dimensi. Karya-karya tersebut merupakan karya dari seniman Kris Kuksi dan Mark Castator. Mereka membuat karya seni tiga dimensi berbahan metal dan merangkainya hingga membentuk karya seni tiga dimensi.

Kris Kuksi adalah seorang seniman Amerika yang lahir di Springfield Missouri dan tumbuh di negara tetangga Kansas. Ia menciptakan karya instalasi yang kompleks bergenre fantastik realisme. Karya-karyannya banyak digambarkan sebagai sebuah penelitian mengingatkan kita pada peradaban yang hilang. Karya telah Kris Kuksitelah ditampilkan di lebih dari 100 pameran di seluruh dunia, termasuk pameran seni satelit Art Basel, Pulse (Los Angeles dan Miami) dan Ruang Lingkup (Basel dan Miami), Liste Köln selama Cologne Art fair di Jerman dan Portrait Gallery Smithsonian National dalam pameran "The Outwin Boochever Kompetisi Portrait". 


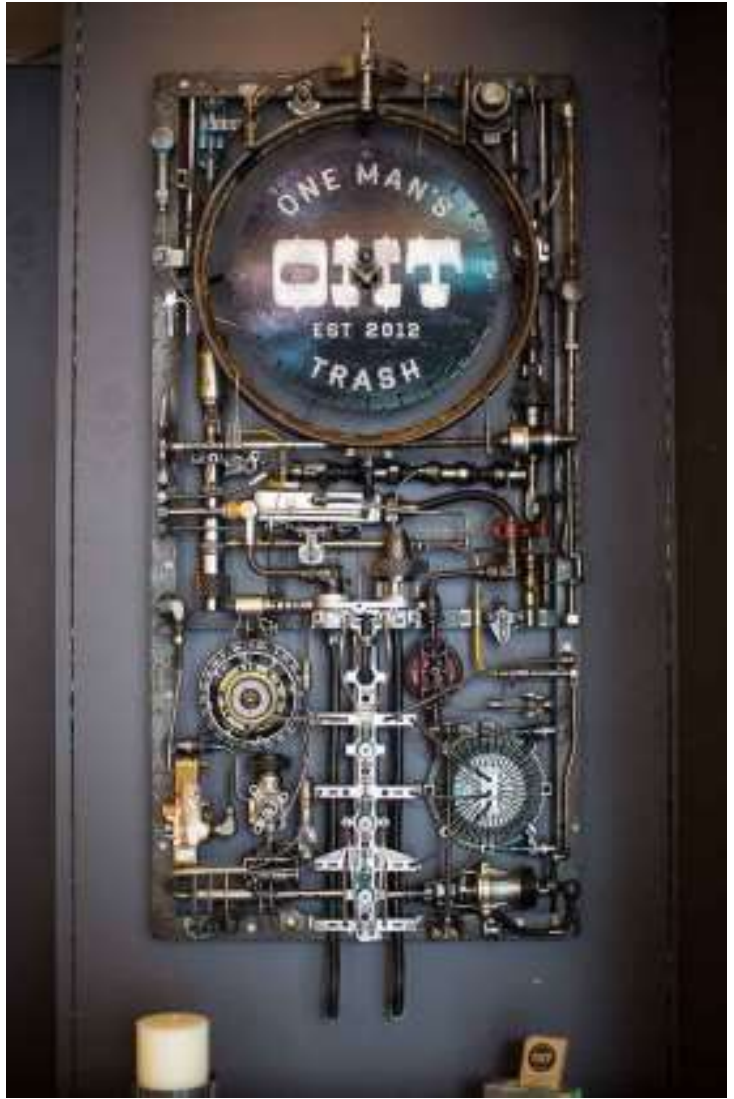

Gambar 1. Kris Kuksi 1

Seniman lain yang juga menggunakan mesin-mesin dalam karyanya adalah Greg Brotherton. Greg lahir di Ames, lowa, pada tahun 1968. Minatnya dalam mekanik muncul pada usia lima, ketika ia mulai membongkar apa-apa dengan sekrup di dalamnya. Pada usia dua belas ia telah belajar sendiri untuk menambang halaman belakang rumahnya dengan bahan peledak buatan sendiri (tidak ada cedera!). Pada tahun 1987, setelah menerima gelar di desain grafis dan pindah ke California. Selama dua dekade berikutnya, ia menjadi meraih penghargaan seni dan mengasah keterampilannya sebagai pematung.

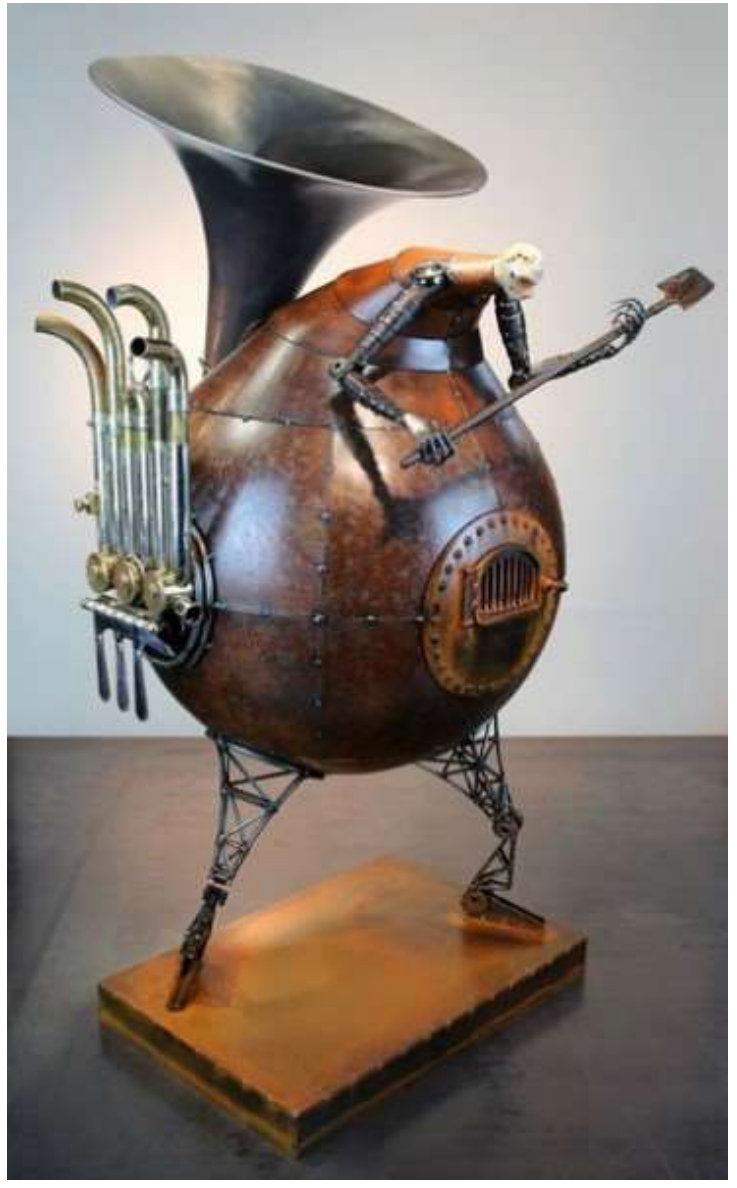

Gambar 2. 4 Sounding The Furnace

\section{METODE PENELITIAN}

Penciptaan sebuah karya seni tidak lepas dari adanya metode-metode yang digunakan dalam menciptakan karya. Ada beberapa tahap yang harus dilakukan untuk memperoleh hasil penciptaan yang maksimal. Tahapan-tahapan tersebut haruslah sistematis dan terencana mulai dari awal penciptaan sampai pada akhir tahapan perwujudan karya. Gustami mengungkapkan bahwa secara metodelogis proses lahirnya suatu karya melalui tiga tahapan utama, yaitu (1) eksplorasi, meliputi langkah pengembaraan jiwa, dan penjelajahan dalam menggali sumber ide. Dari kegiatan ini akan ditemukan tema dan berbagai persoalan. Langkah kedua adalah menggali landasan teori, sumber dan referensi serta acuan visual untuk memperoleh konsep pemecahan masalah (2) Perancangan, yang terdiri dari kegiatan 
menuangkan ide dari hasil analisis yang telah dilakukan ke dalam bentuk dua dimensional, atau desain. Hasil perancangan tersebut selanjutnya diwujudkan dalam bentuk model dan (3) perwujudan, merupakan perwujudan dari model menjadi karya(Gustami, 2004:3).

Metode ini akan digunakan penulis untuk menghasilkan sebuah karya tiga dimensi yang maksimal. Mulai dari mengeksplorasi bentuk kepala sapi, menuangkan ide-ide kreatif dalam bentuk rancangan kemudian mewujudkannya dalam bentuk seni patung tiga dimensi.

Teknik yang digunakan dalam perwujudan karya seni adalah konstruksi menggunakan teknik rakit las dan sekrup. Pengelasan (welding) adalah salah salah satu teknik penyambungan logam dengan cara mencairkan sebagian logam induk dan logam pengisi dengan atau tanpa tekanan dan dengan atau tanpa logam penambah dan menghasilkan sambungan. Berdasarkan definisi dari DIN (Deutch Industrie Normen) las adalah ikatan metalurgi pada sambungan logam paduan yang dilaksanakan dalam keadaan lumer atau cair. Dari definisi tersebut dapat dijabarkan lebih lanjut bahwa las adalah sambungan setempat dari beberapa batang logam dengan menggunakan energi panas.

Baut atau sekrup adalah suatu batang atau tabung dengan alur heliks pada permukaannya. Penggunaan utamanya adalah sebagai pengikat (fastener) untuk menahan dua objek bersama, dan sebagai pesawat sederhana untuk mengubah torsi (torque) menjadi gaya linear. Baut dapat juga didefinisikan sebagai bidang miring yang membungkus suatu batang. Sebagian besar baut dipererat dengan memutarnya searah jarum jam, yang disebut ulir kanan. Baut dengan ulir kiri digunakan pada kasus tertentu, misalnya saat baut akan menjadi pelaku torsi berlawanan arah jarum jam. Dalam seni tiga dimenasi, sekrup atau baut biasa digunakan untuk menyambungkan satu bagian patung dengan bagian yang lain. Demikian dalam pencipkaan karya ini peneliti menggunakan sekrup untuk menyatukan bagian-bagian mesin hingga menjadi bentuk yang diinginkan.

\section{Eksplorasi Dan Penggabungan Mesin Pada Seni Patung \\ Proses penciptaan karya seni} merupakan suatu proses perwujudan sebuah ide menjadi sebuah bentuk karya seni. Proses penciptaan ini melibatkan alat dan material.dalam penciptaan ini, penulus menggunakan beberapa alat material dan teknik. Penelitian ini menggunakan teknis las dalam sekrupdalam merangkai materian menjadi bentuk patung tiga dimensi sesuai yang diharapkan.

Pengelasan (welding) adalah salah satu teknik penyambungan logam dengan cara mencairkan sebagian logam induk dan logam pengisi dengan atau tanpa tekanan dan dengan atau tanpa logam penambah dan menghasilkan sambungan.

Lingkup penggunaan teknik pengelasan dalam kontruksi sangat luas, meliputi perkapalan, jembatan, rangka baja, bejana tekan, pipa pesat, pipa saluran, dan sebagainya.

Disamping untuk penyambungan, proses las dapat juga dipergunakan untuk reparasi misalnya untuk mengisi lubang-lubang pada coran. Membuat lapisan las pada perkakas mempertebal bagian-bagian yang sudah aus, dan macam -macam reparasi lainnya.

Pengelasan bukan tujuan utama dari kontruksi, tetapi merupakan sarana untuk mencapai ekonomi pembuatan yang lebih baik. Karena itu rancangan las dan cara pengelasan harus betul-betul memperhatikan dan memperlihatkan kesesuaian antara sifatsifat lasdengan kegunaan kontruksi serta kegunaan disekitarnya. 
a. Alat

1. Blower Api

Alat ini digunakan untuk membakar kepala sapi yang telah dibersihkan. Tujuannya agar kepala sapi bebas dari rambut atau bulu agar cetakan yang dibuat tidak rusak. Selain itu, blower api juga digunakan untuk memanaskan logam yang akan dikenteng daan selam dilakukan proses pengentengan logam.

2. Gerinda

Alat ini digunaka untuk merapikan dan menyempurnakan bentuk modeling yang telah dihasilkan. Gerinda juga digunkan untuk memotong dan merapikan bentuk akhir patung yang dihasilkan.

3. Alat Las

Pengelasan dengan oksi asetilin adalah proses pengelasan secara manual dengan pemanasan permukaan logam yang akan dilas atau disambung sampai mencair oleh nyala gas asetilin melalui pembakaran $\mathrm{C} 2 \mathrm{H} 2$ dengan gas $\mathrm{O} 2$ dengan atau tanpa logam pengisi.

Untuk memperoleh nyala pembakaran yang baik perlu pengaturan campuran gas yang dibakar. Jika jumlah gas $\mathrm{O} 2 \mathrm{di}$ tambah maka akan dihasilkan suhu yang sangat tinggi, lebih tinggi dari pada suhu lebur baja atau metal lainnya, sehingga dalam waktu sekejap mampu mencairkan logam tersebutyang cukup tebal.

4. Landasan untuk memukul / Anvil Landasan ini terdapat tiga macam yaitu landasan yang terbuat dari kayu, besi dan bahan campuran pengikat kelenturan logam yang disebut sebagai jabung.

5. Bor

Mesin bor adalah suatu jenis mesin gerakanya memutarkan alat pemotong yang arah pemakanan mata bor hanya pada sumbu mesin tersebut (pengerjaan pelubangan). Sedangkan Pengeboran adalah operasi menghasilkan lubang berbentuk bulat dalam lembaran-kerja dengan menggunakan pemotong berputar yang disebut bor dan memiliki fungsi untuk Membuat lubang, Membuat lobang bertingkatm, Membesarkan lobang, Chamfer. Cara kerja mesin bor adalah dengan cara memutar mata pisau dengan kecepatan tertentu dan ditekan ke suatu benda kerja.

\section{Material /Bahan}

Ada beberapa bahan yang digunakan dalam pembuatan karya dimensi ini. Bahan-bahan tersebut adalah bahan-bahan recycle yang sudah tidak digunakan lagi atau seringkali menjadi sampah.

\section{Tabung gas}

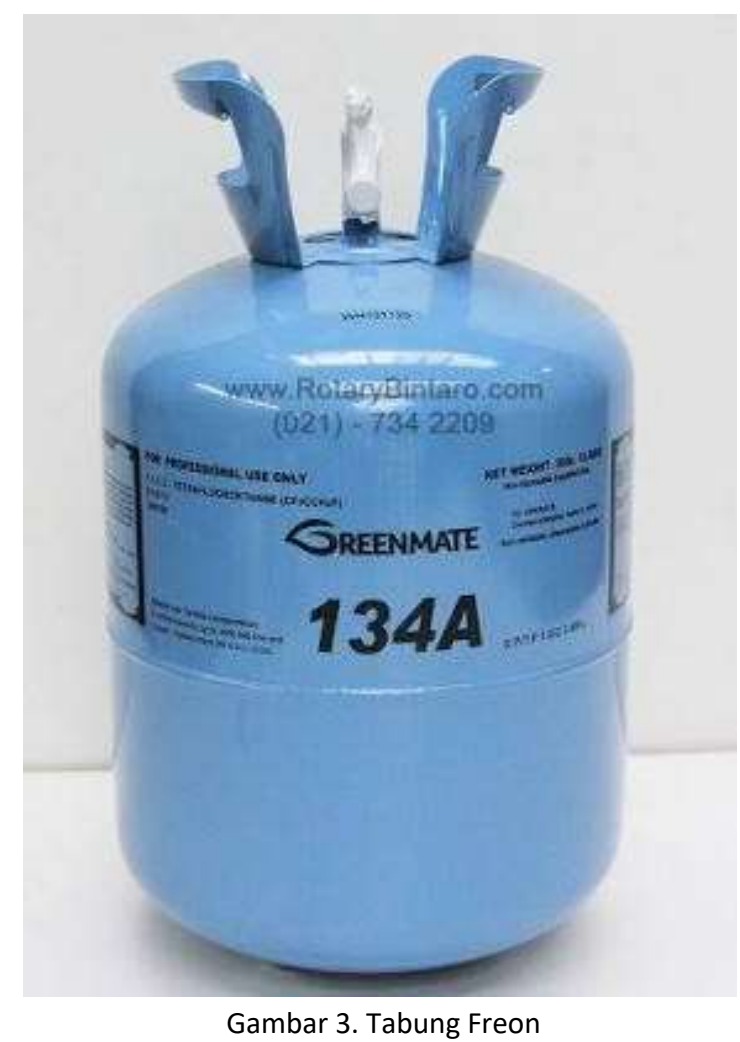




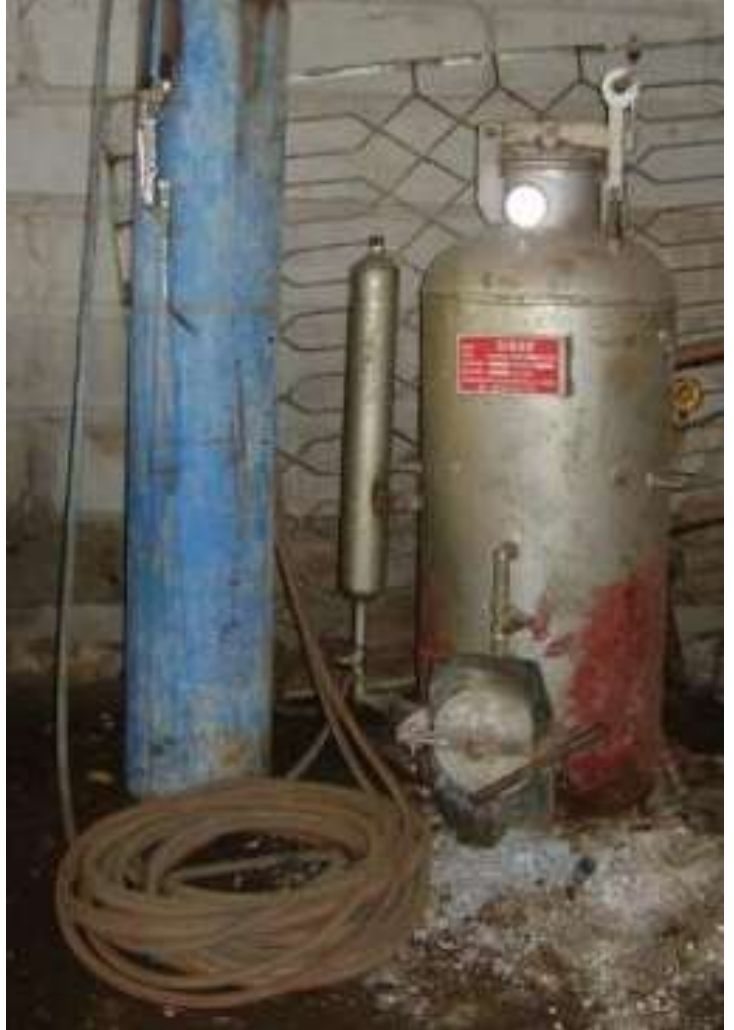

Gambar 4. Tabung Las Karbit

\section{Pipa-pipa bekas}

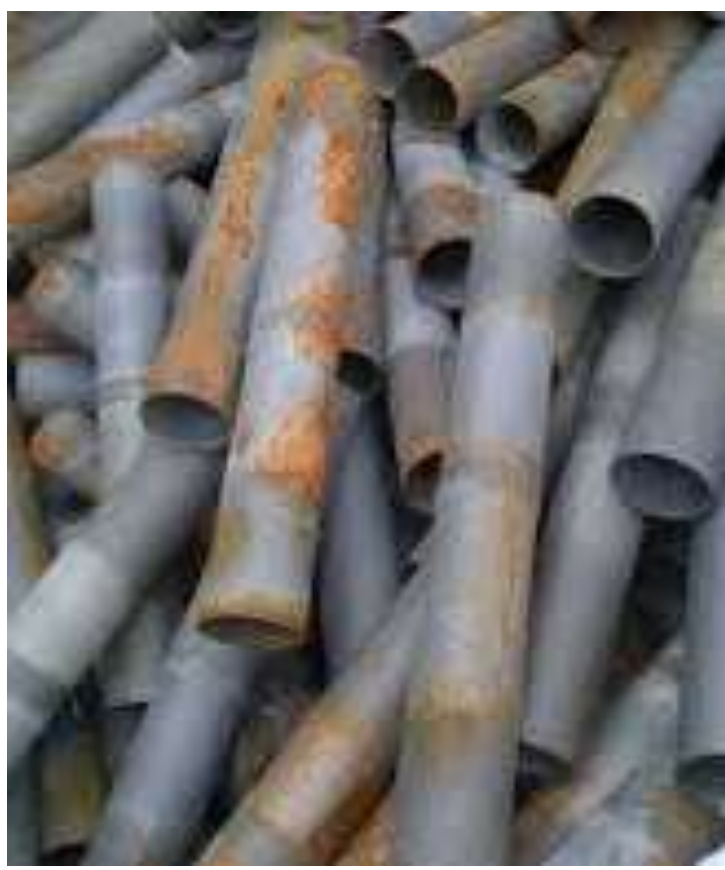

Gambar 5. Besi Pipa Bekas
3. Block-block mesin kendaraan baik mobil

maupun motor

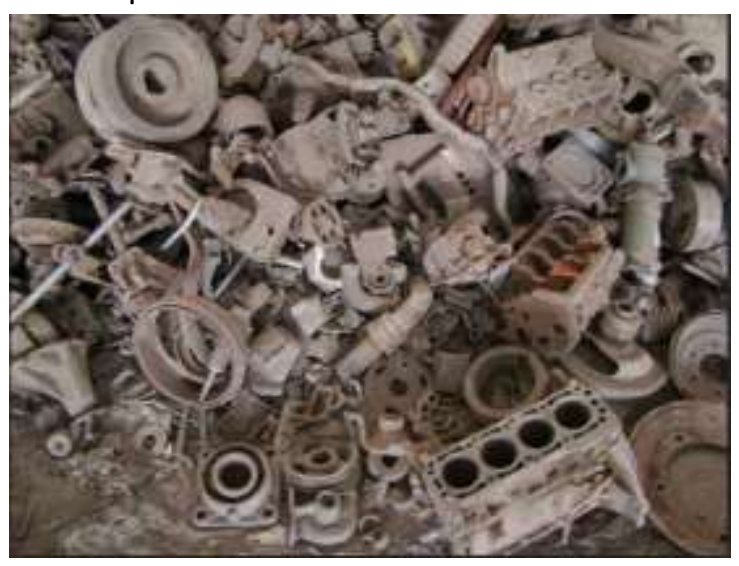

Gambar 6. Sampah Mesin Motor

4. Lampu motor

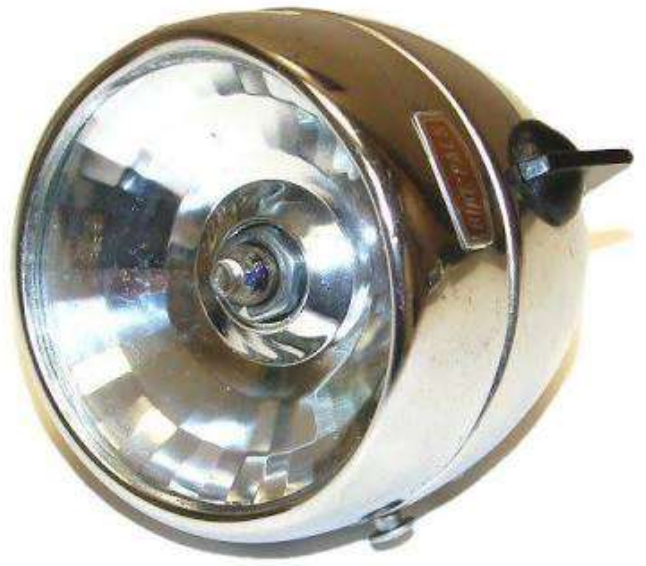

Gambar 7. Lampu Motor

5. Barang-barak ricycle yang terbuat dari logam

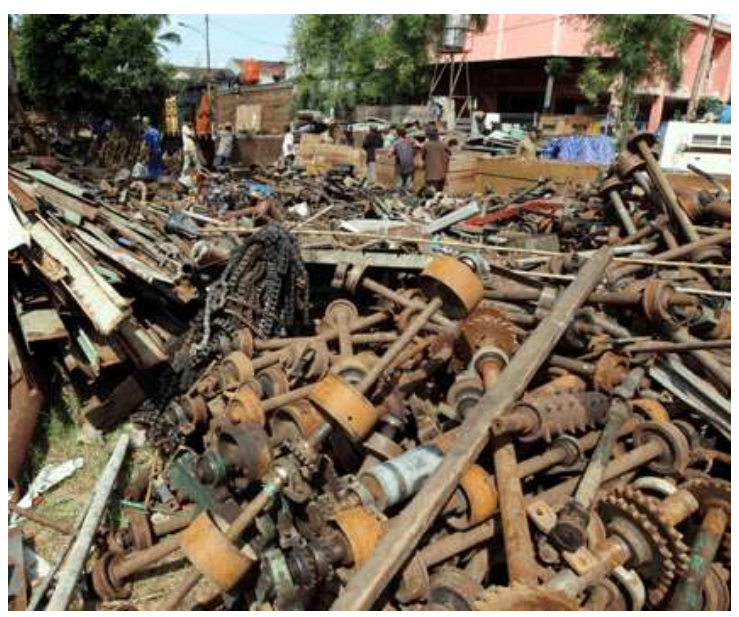

Gambar 8. Sampah Mesin Mobil 


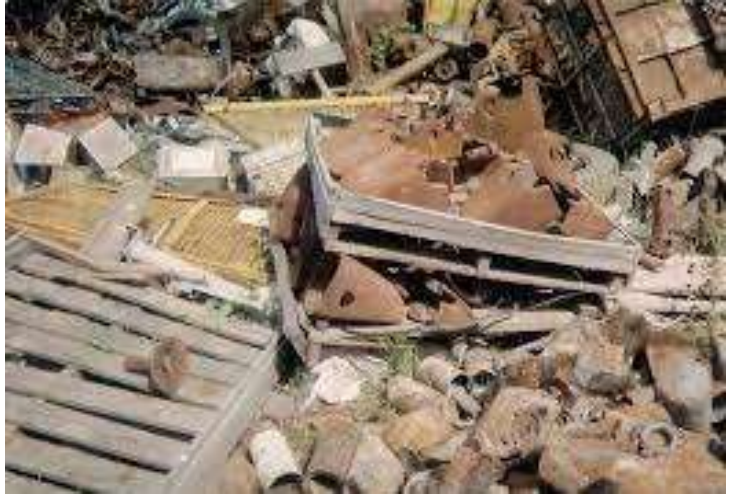

Gambar 9. Sampah Besi Tua

\section{Cara pembuatan}

Pembuatan patung tiga dimensi ini melalui beberapa tahapan. Dimulai dari pengumpulan bahan-bahan atau material yang akan digunakan. Setelah semua bahan dikumpulkan dan dipilih, langkah selnjutnyan yaitu membersihkan. Blok-blok mesin yang kotor dengan debu dan oli dibersihkan dengan menggunakan bensin atau premium. Dengan menggunakan kuas, satu persatu mesin dibersihkan hingga benar-benar bersih. Pembersihan ini bertujuan agar ketika di las atau di cat, dapat tersambung dan menempel dengan sempurna.

Langkah selanjutnya yaitu pengelasan. Satu persatu pipa dilas disambung sebagai kerangka diletakkannya mesin-mesin atau material besi lainnya. Satu persatu besi-besi dan blok-blok mulai dilas disamnung mengikuti bentuk yang diinginkan. Dalam menyambung material, perlu dilihat tebal tipisnya mesia yang akan dilas. Material atau besi yang tebal berbeda pengelasannya dengan besi yang tipis. Besi tipis tidak bisa terlalu lama terkena api pengelasana. Hal ini dikarenakan apabila besi tipis terlalu lama atau terlalu panas, dia akan membentuk lubang yang tidak semestinya atau tidak kita harapkan.

Setelah semua bahan telah sempurna disatukan, langkah selanjutnya adalah pembersihan. Pembersihan disini adalah pembersihan kerak bekas las sehingga hasil las terlihat lebih rapi dan juga pembersihan jelaga bekas las. Tujuan pembersihan adalah agar patung terlihat rapi dan ketika dilakukan proses pengecatan, cat dapat menempel sempurna.

Sebagai finishing karya dilakukan pengecatan atau pewarnaan. Pengecatan ini dimulai dari pengecatan dasar menggunakan cat epoxi. Tujuannya agar logam tidak mudah berkarat. Cat yang digunakan adalh cat warna merah, biru, kuning dan hitam. Dengan pengecatan ini maka patung akan terlihat lebih sempurna dan material yang digunakan akan lebih awet.

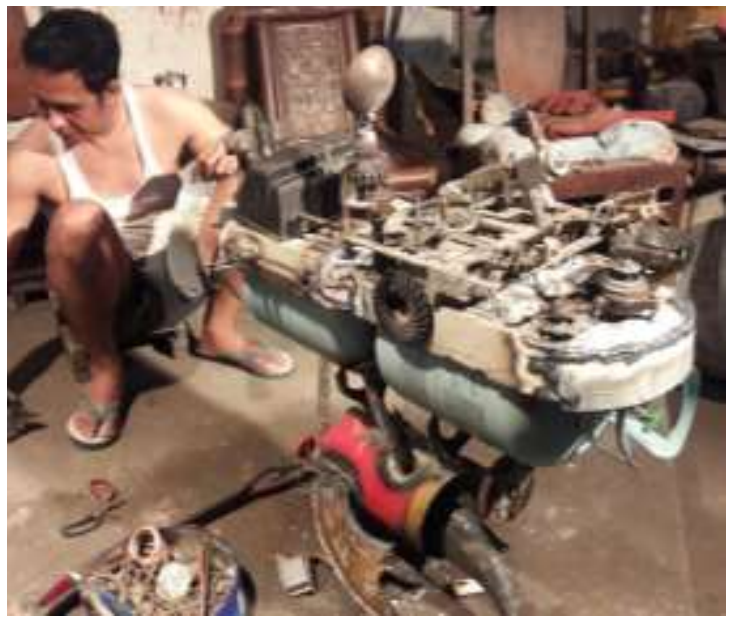

Gambar 10. Perakitan Material

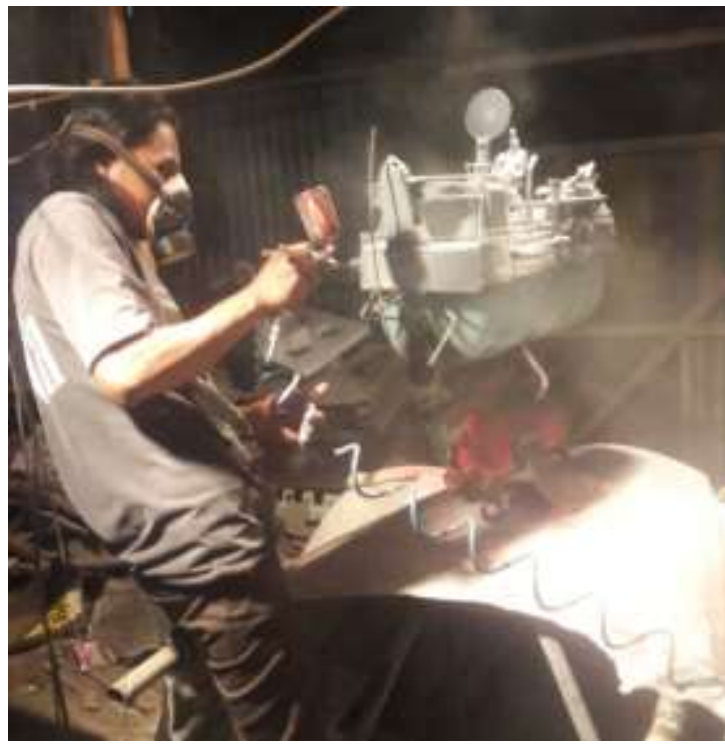

Gambar 11. Proses Pengecatan 


\section{Hasil Karya}

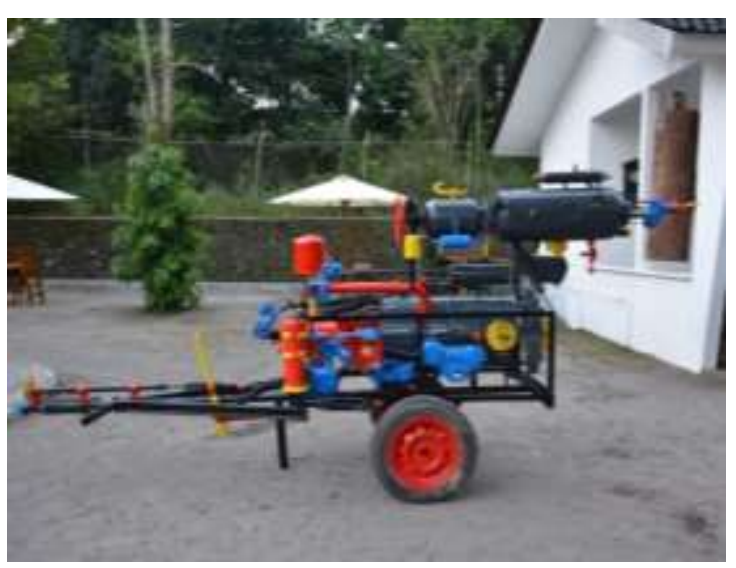

Gambar 12. Karya 1 Tampak Samping

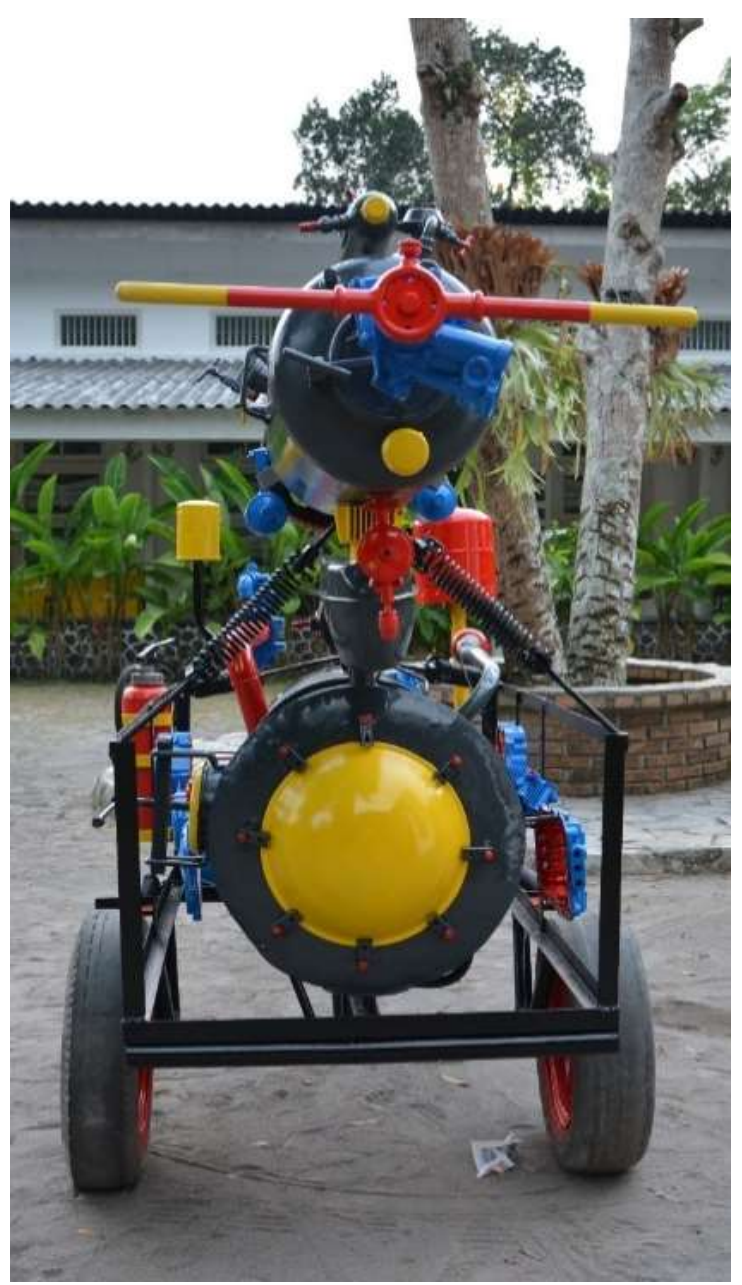

Gambar 13. Karya 1 Tampak Depan

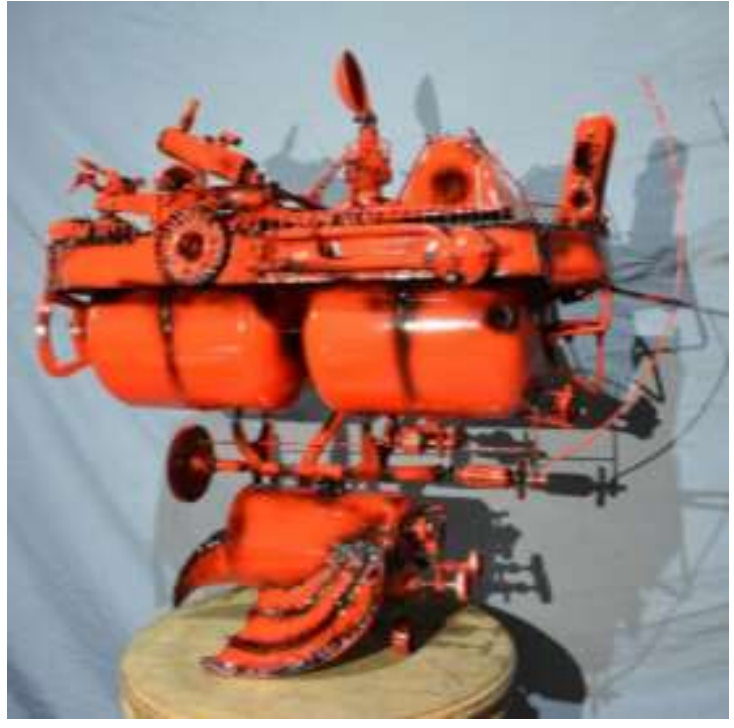

Gambar 14. Karya 2 Tampak Samping

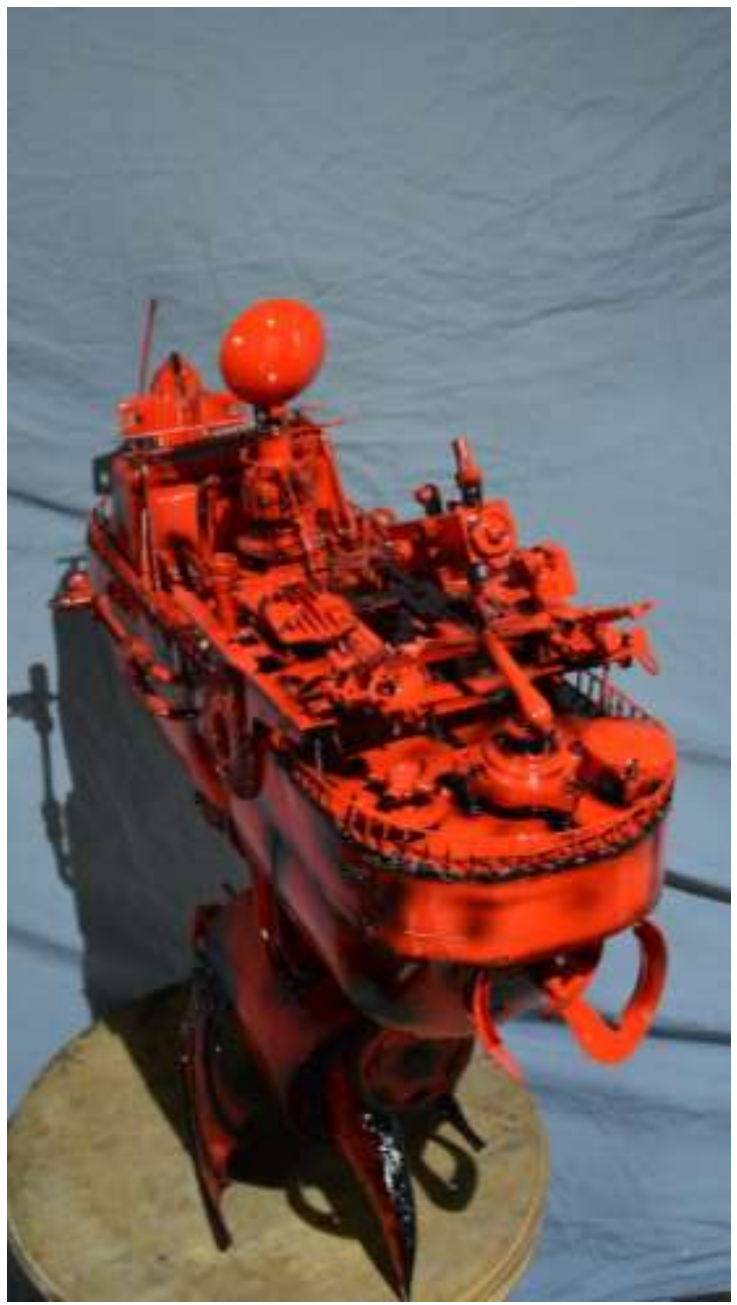

Gambar 15. Karya 2 Tampak Atas 


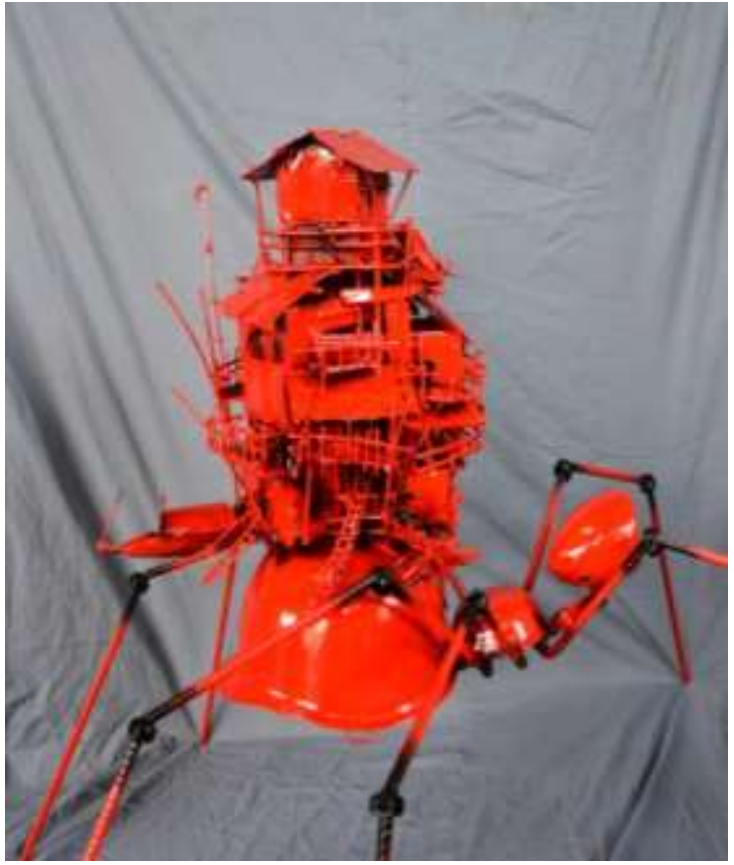

Gambar 16. Karya 3 Tampak Samping

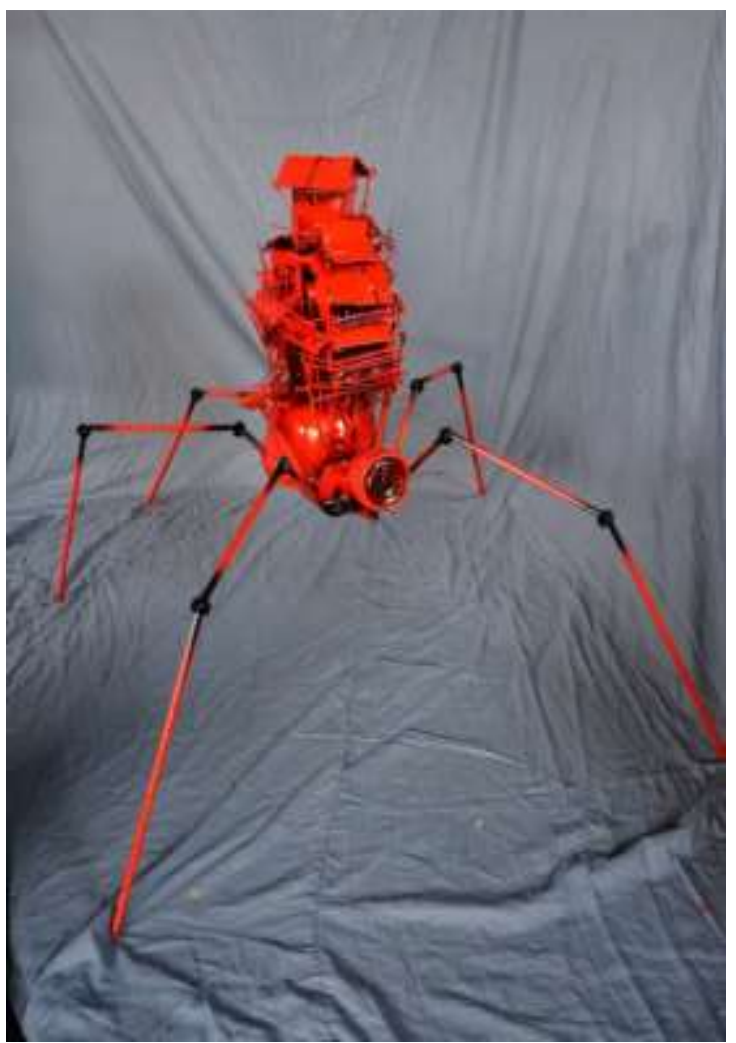

Gambar 17. Karya 3 Tampak Depan

\section{KESIMPULAN}

Sebuah karya seni lahir dari pemikiran seorang seniman yang didasari pada ide-ide yang didapat melalui proses observasi. Ada bermacam-macam karya patung yang dibuat dengan berbagai macam teknik. Bahan-bahan yang sering digunakan seperti fiber, logam, dan kayu. Teknik yang digunakanpun bermacam-macam. Mulai dari teknik cetak, teknik cor, teknik rakit hingga teknik las. Semua bahan mau teknik tersebut diaplikasikan hingga menghasilkan karya tiga dimensi yang didalamnya terkandung makna yang ingin disampaiakan oleh sang seniman.

Salah satu material yangunik dan coba didaur ulang hingga menghasilkan karyas seni adalah sampah-sampah logam yangbanyak dijumpai di pasar loak. Dengan berbagai bentuk dan model, material-material tersebut dapat digunakan, disusun sedemikian sehingga membentuk sebuah karya tiga dimensi. Selain mengurangi sampah logam, karya yagn dihasilkan juga akan memberikan kepuasan batin bagi pembuatnya dan bisa menjadi media penyampaian moral bahwa sampah seperti limbah mesin mobil atau motor yang sudah menjadi limbah bisa disulap menjadi karya seni tiga dimensi yang luar biasa.

\section{DAFTAR PUSTAKA}

Bastomi, Suwaji, Wawasan Seni, IKIP Semarang Press, Semarang, 1990

Gustami, SP, Proses Penciptaan Seni kriya: Untaian Metodologis, Program Pasca Sarjana Institut Seni Indonesia, Yogyakarta, 2004

Soedarso SP, Tinjauan Seni: Sebuah Pengantar untuk Apresiasi Seni, Saku Dayar Sana, Yogyakarta, 1988 
148 ]

Soeprapto, Teknik Pelapisan, FPTK IKIP, Yogyakarta, 1994

Williams Arthur, 2005, The Sculpture Reference Illustrated: Contemporary Techniques, Terms, Tools, Materials, And Sculpture, Sculpture Books, University of Michigan, USA

\section{Sumber Internet:}

http://www.brotron.com/X/gallery2.html http://www.dailyartmuse.com/category/reart/page/10/

https://www.kuksi.com/ 